Katja Görlitz and Marcus Tamm*

\title{
Panel Data on Training Activities - Voucher Recipients and Eligible Employees of the Program Bildungsprämie
}

DOI 10.1515/jbnst-2015-1041

\section{Introduction}

Many countries in Europe have introduced training voucher programs to increase adults' training participation that was set as a political aim on the European level. In December 2008, the training program „Bildungsprämie“ was implemented in Germany on the federal level. The main component of the program was a training voucher (Prämiengutschein) that reduced training costs by 50 percent up to a maximum subsidy of 500 Euro. Individuals eligible for the voucher include employees or self-employed with a maximum taxable income of 25,600 Euro for singles and 51,600 Euro for couples as well as individuals on maternity or parental leave. ${ }^{1}$ In relation to all German employees, approximately two thirds of the German workforce was eligible for the voucher. In 2009, the Federal Ministry of Education and Research (BMBF) contracted the RheinischWestfälisches Institut für Wirtschaftsforschung (RWI), the Gesellschaft für Innovationsforschung und Beratung (GIB Berlin) and the Institute for Applied Social Sciences (infas) to evaluate the effectiveness of this training program. ${ }^{2}$

In this paper, we describe the data that was collected for the evaluation of the program. ${ }^{3}$ Two different samples of individuals were surveyed by telephone: First, those individuals receiving a training voucher in 2010, henceforth referred

1 The maximum amount of the voucher and the income limits were changed several times. In the following, the information on the program refers to conditions valid in 2010, because recipients from 2010 are the group that was interviewed in the survey.

2 For the description of the evaluation design and the results of the program evaluation, see RWI et al. (2012).

3 Dehos et al. (2016) contains a more detailed data description.

*Corresponding author: Marcus Tamm, RWI, Invalidenstr. 112, 10115 Berlin, Germany, E-mail: tamm@rwi-essen.de

Katja Görlitz, FU Berlin, Boltzmannstr. 20,14195 Berlin, Germany, E-mail: katja.goerlitz@fu-berlin.de 
to as voucher recipients, and, second, eligible employees. The first wave of the data was collected in 2010 and the second wave in 2011. To document potential changes in the composition of voucher recipients throughout the year 2010, the data was conducted in four cohorts covering information from the first to the fourth quarter. For reasons of comparability, the survey of eligible employees followed this cohort structure. For voucher recipients, a third wave on a largely reduced number of questions was carried out in June/July 2012. The survey on voucher recipients consists of 5,119 observations in the first wave. In the second and third wave, the number of observations was reduced to 2,210 and to 1,043 observations, respectively. The survey on eligible employees contains 6,075 observations in the first wave and 3,136 observations in the second wave.

The majority of questions are identical in both surveys: socio-demographics, the retrospective employment history, work-related characteristics, wages, education and training (including the characteristics of training). For voucher recipients, additional questions on their experiences with the voucher program were posed. For eligible employees, an experiment was implemented in the form of providing information on the voucher program to half of the randomly-chosen employees, while not providing this information to the other half.

Due to the manifold questions asked in the questionnaire, the data is suitable to investigate a variety of research questions for the group of lowand medium-income employees. In the following, we give some examples:

- Training behavior (in particular, incidence and intensity as well as training characteristics including the monetary costs and the support by employers), reasons for non-participation, an assessment on the importance of lifelong learning and knowledge about educational and training programs in Germany;

- Labor market status and dynamics;

- Occupation, tasks, responsibilities and their changes across time;

- Job satisfaction.

The remainder of this paper is organized as follows. The next two sections describe the sample design and implementation of the surveys for voucher recipients and eligible employees, respectively. In the fourth section, the contents of the questionnaires are described. Finally, information on data access is provided.

\section{Voucher recipients}

The target population of voucher recipients was defined based on the administrative records containing all voucher recipients. It covered all voucher 
recipients in 2010 for whom a voucher was issued in one of the four time periods: (i) from February to first week of March, (ii) April to first week of May, (iii) July and (iv) September to first week of October 2010. This cohort design was chosen (amongst other reasons) to conduct the interviews as shortly as possible after voucher receipt to observe individuals before voucher redemption and training participation (on average, interviews took place around 6 weeks after voucher receipt). In this population, telephone numbers had been provided for 80 percent during voucher application or could be recovered by telephone number search. Survey participants were drawn randomly from those voucher recipients for whom telephone numbers were available. In the first wave in 2010, 5,119 interviews could be conducted and the rate of response was very high (83 percent). One target of the first wave was to obtain information on voucher recipients' experiences with the application process of the voucher and on their labor market status and job characteristics before participation in the voucher-financed training course. A detailed description of the content of the questionnaires can be found in section 4, separately by interview wave.

In 2011, the second interview was targeted at identifying changes in labor market outcomes occurring during the 12 months after initial contact. ${ }^{4}$ For cost-efficiency reasons, the intended number of realized interviews was reduced to approximately 2,000 and the sample was stratified according to the status of voucher redemption at the time of the first interview. Specifically, recipients who had not redeemed their voucher at the time of the first interview were more likely to be surveyed in the second wave, while only a small number of recipients were sampled again who already had finished the voucher-financed training in the first wave. This was important for the evaluation design to estimate training returns which required information before and after course participation for persons who redeemed their voucher for training participation and for a control group of persons who were abstained from redeeming their voucher by an exogenous reason like course cancellation by the provider of training. ${ }^{5}$ In the second wave (2011), 2,210 interviews could be realized successfully which relates to a response rate of 88 percent.

\footnotetext{
4 Most interviews were conducted exactly 12 months after the first interview (54 percent). For 3 percent of the interviewees the time span was 10 months, for 23 percent it was 11 months, for 19 percent it was 13 months and for less than 1 percent it was 14 months.

5 For results on the returns to training financed by the Bildungsprämie, see Görlitz and Tamm (2016a).
} 
The third interview with voucher recipients was conducted in 2012 to identify changes in labor market outcomes occurring in the medium run, i. e. up to 24 months after training participation. Only persons were considered for the third interview who were interviewed successfully in the first two waves and who participated in cohorts (i) to (iii). The cohort design has not been followed in the third wave and all interviews were realized between June and July 2012. Again, the sample was stratified by status of voucher redemption, this time measured at the time of the second interview. For the evaluation, it was important to interview all persons again who did not redeem their voucher due to an exogenous reason until the third wave to keep the size of this control group as large as possible. Individuals who participated in a voucher-financed course according to their second wave interview were chosen randomly for the third wave. Persons not redeeming their voucher because of an endogenous reason were not considered at all. In the third wave, 1,043 voucher recipients were interviewed corresponding to a response rate of 84 percent.

\section{Eligible employees}

As already mentioned, the voucher is available for persons with low or medium household income if they are employed, self-employed or on maternity or parental leave. Since there is no single data set covering the universe of these individuals and for cost efficiency reasons, it was decided to primarily focus on eligible employees. ${ }^{6}$ The sample was drawn from administrative records of the social security system covering all employees contributing to the social security system during the year 2008. Defining the target population from these records is not trivial, because taxable income depends e. g. on marital status, own individual income as well as partner's income while the administrative records only include individuals' labor income. Therefore, it was necessary to ask all relevant questions in the survey and then decide about eligibility during the interview. To keep the number of interviews with non-eligible employees as small as possible, individuals with low or medium labor income in the administrative records were sampled with a much higher probability than individuals with high labor income.

6 Among persons eligible for the voucher, the group of employees accounts for almost 90 percent. 
In the first wave in 2010, 6,075 employees could be interviewed (corresponding to a response rate of 35 percent) of whom 5,062 employees were identified as being eligible for the program. In the second wave, a reduced sample of randomly selected respondents, who had declared their agreement and were eligible for the program, were re-contacted. All in all, 3,136 interviews could be realized successfully which relates to a response rate of 71 percent.

In addition to collecting information on individuals' personal, labor market and work characteristics, an experiment was implemented in the first interview. In the experiment, a random 50 percent of the eligible employees were informed about the general principle of the training voucher, its conditions and on how to obtain the voucher. ${ }^{7}$ A detailed description of all contents of the questionnaires by survey wave can be found in section 4 .

\section{Content of the questionnaires}

Table 1 documents which information is contained in the surveys of voucher recipients and of eligible employees by interview wave. Complete questionnaires are included in Dehos et al. (2016).

Table 1: Description of variables.

\begin{tabular}{|c|c|c|c|c|c|c|}
\hline \multirow[t]{2}{*}{ Topics } & \multirow[t]{2}{*}{ Variables } & \multicolumn{3}{|c|}{ Voucher recipients } & \multicolumn{2}{|c|}{$\begin{array}{l}\text { Eligible } \\
\text { employees }\end{array}$} \\
\hline & & 1. wave & 2. wave & 3. wave & 1. wave & 2. wave \\
\hline Sociodemographics & $\begin{array}{l}\text { Gender, age, nationality, } \\
\text { marital status, children }\end{array}$ & $\mathrm{x}$ & $x$ & & $x$ & $\mathrm{x}$ \\
\hline Education & $\begin{array}{l}\text { Highest educational } \\
\text { degree }\end{array}$ & $\mathrm{x}$ & $\mathrm{x}$ & $X^{*}$ & $\mathrm{x}$ & $\mathrm{x}$ \\
\hline $\begin{array}{l}\text { Employment status } \\
\text { and biography }\end{array}$ & $\begin{array}{l}\text { Current employment status } \\
\text { and employment } \\
\text { biography }\end{array}$ & $X$ & $x$ & $X^{*}$ & $x$ & $\mathrm{x}$ \\
\hline $\begin{array}{l}\text { Characteristics of } \\
\text { current } \\
\text { employment }\end{array}$ & $\begin{array}{l}\text { Working hours, tenure, } \\
\text { temporary contract, tasks, } \\
\text { responsibilities, job } \\
\text { satisfaction }\end{array}$ & $x$ & $x$ & $X^{*}$ & $X$ & $\mathrm{x}$ \\
\hline Wages & Gross monthly wages & $\mathrm{X}$ & $\mathrm{X}$ & $X^{\star}$ & $\mathrm{X}$ & $\mathrm{x}$ \\
\hline
\end{tabular}

7 Görlitz and Tamm (2016b) analyze the effects of the information intervention. 
Table 1: (continued)

\begin{tabular}{|c|c|c|c|c|c|c|}
\hline \multirow[t]{2}{*}{ Topics } & \multirow[t]{2}{*}{ Variables } & \multicolumn{3}{|c|}{ Voucher recipients } & \multicolumn{2}{|c|}{$\begin{array}{l}\text { Eligible } \\
\text { employees }\end{array}$} \\
\hline & & 1. wave & 2. wave & 3. wave & 1. wave & 2. wave \\
\hline $\begin{array}{l}\text { Characteristics of } \\
\text { current employer }\end{array}$ & Firm size, industry & $\mathrm{X}$ & $x$ & & $\mathrm{x}$ & $\mathrm{x}$ \\
\hline Mobility & $\begin{array}{l}\text { Firm mobility (changing } \\
\text { one's employer) }\end{array}$ & & $x$ & $X^{\star}$ & & $\mathrm{x}$ \\
\hline Training biography & $\begin{array}{l}\text { Training participation and } \\
\text { characteristics (e. g. } \\
\text { formal vs. informal } \\
\text { training, duration, } \\
\text { financial support), } \\
\text { assessment of importance } \\
\text { of lifelong learning }\end{array}$ & $x$ & $x$ & $X^{\star}$ & $x$ & $x$ \\
\hline \multirow[t]{2}{*}{$\begin{array}{l}\text { Experience with } \\
\quad \text { Bildungsprämie }\end{array}$} & $\begin{array}{l}\text { Experience with voucher } \\
\text { receipt and with the } \\
\text { counseling office }\end{array}$ & $x$ & & & & \\
\hline & $\begin{array}{l}\text { Experience with the } \\
\text { redemption of the voucher, } \\
\text { information on voucher- } \\
\text { financed training and } \\
\text { assessment (if voucher } \\
\text { was redeemed) }\end{array}$ & $X$ & $\mathrm{x}$ & & & \\
\hline $\begin{array}{l}\text { Knowledge on } \\
\text { training } \\
\text { subsidies }\end{array}$ & $\begin{array}{l}\text { Knowledge on subsidies } \\
\text { for education or training } \\
\text { (including the } \\
\text { Bildungsprämie) }\end{array}$ & & & & $\mathrm{x}$ & $\mathrm{x}$ \\
\hline Experiment & $\begin{array}{l}\text { Information on training } \\
\text { voucher Bildungsprämie } \\
\text { Use of training voucher } \\
\text { Bildungsprämie }\end{array}$ & & & & $50 \%$ & $x$ \\
\hline
\end{tabular}

Note: * In the third wave, the number of questions per topic was largely reduced compared to the first and second wave.

\section{Data access}

A scientific use file including all waves of the surveys of voucher recipients and of eligible employees are available for non-commercial research (data "Bildungsprämie: Programmteilnehmer und Anspruchsberechtigte", http://doi. org/10.7807/Bildung:10-12:V2). The data include all variables from the questionnaires and are enhanced with aggregate statistics measured on the county level 
(e. g. the unemployment rate). Data access is provided by the Research Data Centre FDZ Ruhr am RWI. Further information is available on the homepage of the FDZ Ruhr (fdz.rwi-essen.de).

Previous articles using the data include Görlitz and Tamm (2012, 2016a and 2016b).

Acknowledgments: The data set described in this paper was financed by the Federal Ministry of Education and Research (BMBF), the European Social Fund (ESF) and the European Union. The German title of the data set is "Bildungsprämie: Programmteilnehmer und Anspruchsberechtigte“. For data access please contact fdz@rwi-essen.de.

\section{References}

Dehos, F., Görlitz, K., Schiel, S., Schröder, H., Tamm, M. (2016), Datenbericht Bildungsprämie: Programmteilnehmer und Anspruchsberechtigte, RWI Materialien 108, Essen, RWI.

Görlitz, K., Tamm, M. (2012), Mobilisierung von Erwerbstätigen zur Teilnahme an beruflicher Weiterbildung durch die "Bildungsprämie". Berufsbildung in Wissenschaft und Praxis 1/2012: 27-30.

Görlitz, K., Tamm, M. (2016a), The Returns to Voucher-Financed Training on Wages, Employment and Job Tasks. Economics of Education Review 52: 51-62.

Görlitz, K., Tamm, M. (2016b), Information, Financial aid and Training Participation: Evidence from a Randomized Field Experiment, Ruhr Economic Papers \#615, Essen, RWI.

RWI, GIB and Infas (2012), Datenmonitoring und Evaluation des Programms „Bildungsprämie“, Endbericht 2012. Projekt für das Bundesministerium für Bildung und Forschung. RWI:Projektberichte. Essen. 